\title{
SYMBOLIC OF METAL CALDRONS IN THE NOMAD CULTURE
}

(C) 2017

Jumabekova Gulnara Sainovna, candidate of historical sciences, leading researcher of Prehistoric Department

Bazarbayeva Galiya Appazovna, candidate of historical sciences, leading researcher of Prehistoric Department A.Kh. Margulan Institute of Archaeology (Almaty, Republic of Kazakhstan)

Abstract. The paper briefly traces the symbolic role of the metal caldrons from the Early Iron Age. This category of items can be considered as attributes of the elite and aristocracy. Experts identified the connection of the caldron (kazan) with the funeral rite in the Middle Ages, traced its role as a marker of high social rank people. This dependence is also traced on the example of population change as a whole. These include the Jetysu district (South-Eastern Kazakhstan), the Southern Urals in the era of the early nomads, and the interfluve of the Dnieper and Volga in the late Middle Ages. Burials of men with a cauldron and other attributes of power in the era of the early and medieval nomads, probably indicates the fulfillment of their economic and military duties. The example of the functional purpose of boilers states the succession of the nomadic culture in the use of the power attributes. The value of the metal boiler along with some elements of the object complex (hryvnia, etc.), laid down even in the period of nomad culture development as a symbol of representatives of high rank people, preserved for thousands of years.

Keywords: Eurasia; Jetysu; culture; nomads; early Iron Age; later Middle Ages; cauldron; attributes of power; symbol; social rank; elite; aristocracy; leader; funeral rite; mound; object complex; functional purpose; continuity; feast; sacral marker.

УДК 904 (574.26) (638.3)

\section{НОВОЕ ИЗВАЯНИЕ ЭПОХИ РАННИХ КОЧЕВНИКОВ ИЗ ТУРГАЯ}

(C) 2017

Базарбаева Галия Аппазовна, кандидат исторических наук, ведущий научный сотрудник отдела первобытной археологии

Джумабекова Гульнара Саиновна, кандидат исторических наук, ведущий научный сотрудник отдела первобытной археологии Институт археологии имени А.Х. Маргулана (2. Алматы, Республика Казахстан)

Аннотация. В статье вводятся в научный оборот данные о каменном изваянии эпохи ранних кочевников из Тургая. Данный регион является западным крылом Сарыаки - территории, в историко-культурном отношении занимающей пределы от Шынгыстау на востоке, до Улытау - на западе. Экспедицией Института археологии им. А.Х. Маргулана в полевых сезонах 2015-2016 гг. под руководством авторов в окрестностях п. Ашутасты исследовались памятники тасмолинской культуры. В 2016 г. в ходе раскопок было выявлено изваяние раннего железного века. Находка представляет собой довольно редкий случай местонахождения изваяния в комплексе кургана с каменными грядами. Полевые исследования конструкции с изваянием показали не случайный характер его местонахождения в начале гряды. Лаконичность в передаче антропоморфного образа находит параллели в изваяниях эпохи ранних кочевников Центрального Казахстана. По своему назначению и изобразительным приемам изваяния из Сарыарки сходны с изваяниями Северного Причерноморья. Предполагается, что аспект воинской славы, прослеживаемый в средневековых изваяниях, зародился в эпоху ранних кочевников, о чем свидетельствуют находки стел, каменных изваяний.

Ключевые слова: Тургай; Центральный Казахстан; ранний железный век; тасмолинская культура; средневековье; кочевники; изваяние; курганы с каменными грядами; раскопки; комплекс; ограда; конструктивный элемент; погребальный обряд; телесные атрибуты; стела; антропоморфное изображение; признаки.

В статье в научный оборот вводятся данные об изваянии из могильника Ашутасты-2 (Аркалыкский p-н, Костанайская обл.) из Тургая. Данный регион является западным крылом Сарыарки [1]. В составе могильника находится курган с каменными грядами. Каменное изваяние было выявлено в каменной ограде, представляющей собой начало южной гряды. Этот конструктивный элемент исследовался раскопками в 2016 г. Курган с «усами» (№ 3) - наиболее крупный в могильнике, с юго-восточной стороны основного кургана расположен курган-спутник, от которого в восточном направлении тянутся две каменные гряды. Размеры спутника: диаметр $8 \times 10$ м, высота около $20 \mathrm{~cm}$.

Длина северного «уса» - 110 м; южного - 163 м. Гряды имеют на своих концах конструкции в виде небольших уплощенных оплывших насыпей или ка- менных конструкций. Начало южного «уса» и есть оградка с изваянием. Южный «ус» находится на расстоянии 11 м от кургана-спутника. Расстояние между началом «усов» - 24,6 м; расстояние между окончаниями «усов» - 110 м (расстояние между центрами конструкций).

Изваяние находилось в начале южной гряды, зафиксировано в лежащем состоянии по линии СВ-Ю3 в слое дерна, лицевой частью вверх, головой на СВ. Параметры изваяния: $84 \times 14 \times 26$ см.

В ходе исследования выяснилось, что конструкция, где первоначально находилось изваяние, представляет собой подквадратную в плане ограду, ориентированную углами по странам света. Внутреннее пространство ограды имеет ровные стенки и определяется вертикально стоящими блоками и стеловидными камнями. Часть стенок сложена из горизон- 
тально уложенных плиток. В целом камни установлены и уложены таким образом, что соединение горизонтально и вертикально установленных камней образует «замок». Зазоры между крупными камнями забутованы более мелкими. Снаружи камни стенок подперты стоящими на ребре плитами. Заполнение конструкции образовано горизонтально уложенными камнями, которые как бы «цепляются» друг за друга. В основании изваяния, под слоем дерна, выявлена горизонтально лежащая плита, вероятно маркирующая место установки изваяния $(30 \times 20 \mathrm{~cm})$. Нижняя часть изваяния зажата блоком внешней стенки ограды и менее крупными камнями.

Изваяние отличается схематичностью. Голова с трех сторон отделена выемкой, обозначающей шею. Верх головы анфас скруглен, и лицевая часть разде- лена желобком носа на две части. Эта линия носа делит верхнюю часть головы также на две части, позволяя одновременно увидеть здесь дуги бровей или, скорее, прическу. Широкая выемка в нижней части головы позволяет предположить не только желобок, отделяющий голову, но и, возможно, гривну. У него, возможно, намечены руки, обозначены уши. Низким рельефом - желобками - проработаны черты лица нос, глаза; возможно, одновременно под носом полукружьями или скобками обозначен рот. Можно было бы предположить усы, но они, как правило, у изваяний ранних кочевников показаны вислыми. В середине изваяния вниз от линии пояса фиксируется выступ (рис. 1, 1). Иконографически изваяние близко скульптуре скифов Северного Причерноморья [2].
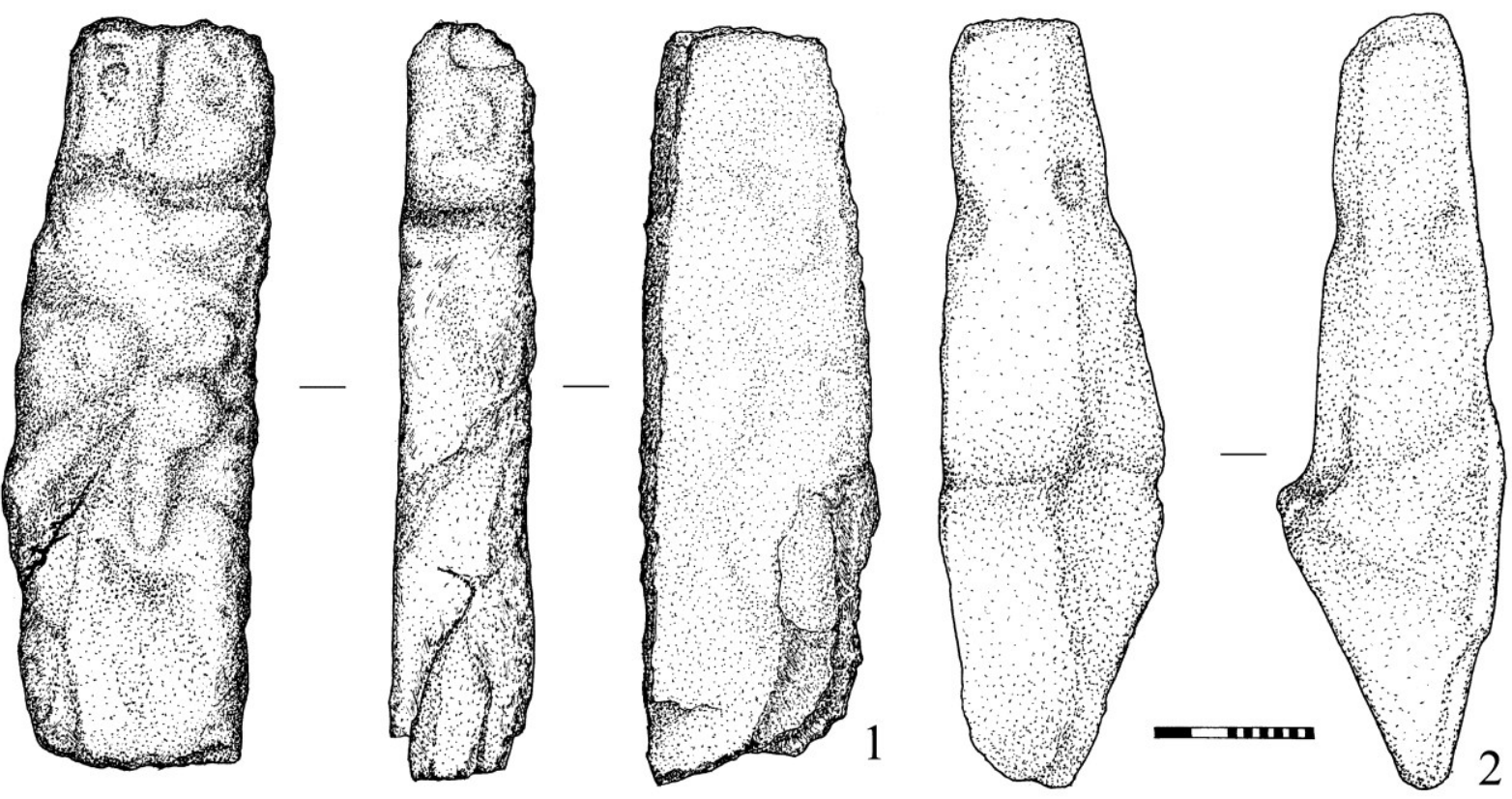

Рисунок 1 - Ашутасты-2. Статуарные памятники. 1 - каменное изваяние; 2- антропоморфная стела

В северной гряде этого же кургана среди камней было выявлено очень схематичное каменное изваяние, скорее - антропоморфная стела. Возможно, использовав форму камня - естественный выступ, мастер смог выделить голову, лицо, выступающее на ровной поверхности прямоугольного в сечении блока с широким ровным основанием (рис. 1, 2).

Об изваяниях и антропоморфных стелах Центрального Казахстана известен целый ряд статей публикация материалов и анализ известного материала [3-5 и др.].

Изваяние из Ашутасты-2 отличает некая условность, стилизованность. Отсутствует отмеченное специалистами сочетание вогнутой или плоской лицевой поверхности и округлой тыльной части [5, c. 130]. По схематизму и лаконизму изваяние из Ашутасты-2 ближе к изваянию с кургана 2 мог. Бегазы. Подобный прием акцентирования глазных впадин без детализации глаз отмечен на изваянии из могильника Атасу и зафиксирован на трех изваяниях с «шишкообразным» атрибутом из Центрального Казахстана. Усы на изваяниях (Атасу, Байдалы) показаны отвислыми. Общим для этих изваяний (Бегазы, Талды-2, Байдалы, Жиланды) является то, что они выполнены тоже без лишней детализации, хотя на изваянии из Ашутаты-2 более правдоподобно выделена голова [4]. Лицо этих изваяний детализировано, реалии тела и предметы вооружения не обозначены, присутствует выступ на голове. Еще более схематичные изваяния из памятников Темир, Косагалы. С изваяниями Каракенгир, Атасу и стелой из Жанатурмыс их объединяет присутствие шишковидного выступа на голове, которое не прослеживается на ашутастинском экземпляре, но сближает отсутствием детализации [6, с. 29]. В целом с этими изваяниями Ашутасты-2 роднит способ передачи черт лица, особенно с бегазинским. Наличие ушей - с изваянием из Талды-2 [4, с. 37]. Изваяние из Ашутасты сближает с бегазинским также наличие руки. Общими для всех изваяний являются определенная композиция (изображение только головы человека), кроме Бегазы. При несомненной лаконичности, можно предположить, что изваяние из Ашутасты-2 все же можно отнести к полуфигурным. Изначально, вероятно, слабопрофилированные детали скульптуры со временем сгладились. Подобный изваянию из Ашутасты-2 прием передачи глаз и носа зафиксирован на отдельных раннескифских изваяниях Причерноморья.

Случаи обнаружения каменного изваяния в комплексе кургана с «усами» довольно редки. В публи- 
кациях указывается на четыре случая в Центральном Казахстане, три из них: изваяние из местности Косагалы (Карагандинская обл.); изваяние с р. Атасу (Карагандинская обл.); изваяние с кургана Жиланды [5; 6 , с. 26]. Еще одно изваяние из комплекса кургана с «усами» находится в фондах Степногорского городского историко-краеведческого музея, обнаружено в 1970-е годы на правом берегу р. Аксу. Помимо рельефа рук, под поясом, ближе к правому боку, косо изображен подпрямоугольный выступ. Судя по положению рук, М.К. Хабдулина предполагает, что это изображение кинжала, заткнутого за пояс, рукоять которого охвачена правой рукой. Этот рельеф также может трактоваться как фаллос. Датировка его VI$\mathrm{V}$ вв. до н.э. Для нас существенно замечание, что хронологическим показателем скифских изваяний VII-V вв. до н.э. является изображение фалла [7].

Обобщение по изваяниям раннего железного века Сарыарки уже сделаны [5]. На ряде изваяний в профильном абрисе голов изваяний Центрального Казахстана фиксируется сочетание плоской поверхности лица и реалистично скошенного затылка (Атасу, Каракенгир, Косагалы, Талды-2). Исследователи констатировали использование такого способа создателями скифских изваяний и изваяний сакской эпохи [5].

Изваяние из Ашутасты демонстрирует признаки, выявленные для серии антропоморфной скульптуры из Центрального Казахстана: воспроизведение глаз углублениями (чаще округлыми); обобщенно проработанный нос, без детализации крыльев; редко обозначенные усы имеют дугообразную форму вниз. Не на всех, но обозначены уши.

На основе анализа расположения вещественных атрибутов (пояс, чекан, кинжал, гривна), высеченных на полуфигурных изваяниях, специалисты произвели систематизацию: чекан изображен всегда на правом боку, на ремешке, который отходит от пояса, или его положение предполагает такую подвеску. Кинжал размещен на передней грани слева (реже - посредине), как правило, горизонтально, рукоятью вправо. Хотя пояс и подвесной ремешок визуализированы только на одном изваянии. Как заметили Ермоленко и Курманкулов, для обозначения оружия на изваяниях обычно показывали пояс, на котором располагалось изображение предметов вооружения. Авторы публикации отмечают, что оружие ударно-колющего или ударно-рубящего действия изображалось на правом боку скифских изваяний [3, с. 158; 5].

Телесные атрибуты представлены в разных сочетаниях на трех изваяниях. Деталь, ассоциирующаяся с фаллосом, обозначена на изваянии из могильника Айбас Дарасы-3. Справедливо отмечено, что факты неоднократного выявления изваяний раннего железного века на территории комплексов с «усами» нельзя признать случайными [5, с. 132]. Для скифских изваяний Причерноморья изображения фаллоса характерно для памятников VI - первой пол. V вв. до н.э. VI-V в. до н.э. [8, с. 239-240]. В отношении изваяния из Ашутасты-2 возникает сомнение в том, что показан предмет вооружения. Оно подкрепляется тем, что нельзя с уверенностью говорить о наличии пояса на изваянии.
Каменные изваяния являются одной из особенностей тасмолинской культуры, которых в Центральном Казахстане насчитывается около 20 [6, с. 32; 9]. Как и стелы, по мнению А.З. Бейсенова, они восходят к культовым камням бегазы-дандыбаевской эпохи [9, с. 124]. Специалист также считает, что культовым назначением памятника, возможно, была обусловлена установка каменного изваяния в насыпи кургана 7 Талды-2 [9, с. 124].

Исследователь памятников тасмолинской культуры А.З. Бейсенов говорит о сотнях курганов с выкладками-«усами», распространение которых совпадает с ареалом памятников тасмолинской культуры Центральный и Северный Казахстан (свыше 300). Остальные 20\% расположены на территории соседних регионов (Восточный, Западный, Южный Казахстан, Жетысу). Для нашей темы изваяний в комплексах курганов с «усами» важен вывод, сделанный А.3. Бейсеновым на основе исследования кургана «с усами» Назар в Карагандинской обл.: найденный в кургане-спутнике железный кинжал, датируемый гунно-сарматским временем [10, с. 88-89], мог быть впущен в более древнее ритуальное сооружение. То есть комплексы курганов с «усами», по-видимому, имели ритуальное значение, которое сохраняли и позже. Датировка курганов «с усами», в частности памятника «37 воинов» - VIII-V вв. до н.э. [11].

Стелы и антропоморфные изваяния раннего железного века, проанализированные С.Ю. Гуцаловым и А.Д. Таировым, по своему назначению сходны с сакскими. Исследователи считают обнаруженные в засыпи ям антропоморфные изваяния изначально установленными на вершинах курганов (Наурзумский р-н, Костанайская обл.). Найденные при сооружении могильной ямы изваяния были установлены в ногах и у головы погребенного [8, с. 243]. В целом, по назначению скифские антропоморфные изваяния делят на две группы. Те, которые устанавливались на вершинах курганов, выражали идею связи с предком-родоначальником. «Изваяния второй группы связаны со специальными культовыми местами и были составной частью жертвенных комплексов святилищ» $[8$, с. 247].

Семантически близки стелам и изваяниям «оленные камни» - раннесакские антропоморфные стелы с изображениями оленей. Д.Г. Савинов установил, что по условиям нахождения оленные камни можно разделить на две большие группы: 1) установленные на специальных «жертвенниках» около мест захоронений; 2) связанные непосредственно с погребениями $[12$, с. 143]. Приведенные выше обстоятельства обнаружения стел и изваяний раннесакского времени из Казахстана демонстрируют схожую картину.

Функциональное назначение оленных камней, установленных на площади курганов, выявили специалисты. «Они олицетворяли собой вертикальную «ось» мира и были предназначены для передачи регламентированных ритуалом ценностей и жертвоприношений. ... В этом отношении принятые атрибуции оленных камней как форм отражения культа дерева, образа мифологического предка или фаллического культа принципиально не противоречат друг другу, хотя явная антропоморфность памятников 
ограничивает круг возможных ассоциаций» [12, c. 147].

Местонахождение каменных стел и раннесакских изваяний на вершине кургана или среди камней крепиды говорит о том, что их устанавливали на последнем этапе погребально-поминального цикла.

Каменные стелы и изваяния в раннесакских памятниках Казахстана функционально выполняли роль, близкую стелам и столбам эпохи поздней бронзы, оленным камням восточных регионов степной Евразии. Раннесакские каменные стелы, оленные камни и изваяния - один из маркеров кочевой культуры I тыс. до н.э. Независимо от того, каковы функции и семантика изваяний, воплощенный в них образ обеспечивал возможность и необходимость «участия» изваяний в совершении обрядов. Эти обряды, в свою очередь, «являлись формами проявления целой группы культов...» [12, с. 117].

По мнению Г.В. Кубарева, древнетюркские изваяния служили изображениями конкретных умерших людей, воинов и уважаемых, богатых, знатных тюрок. В их семантике присутствует аспект воинской славы, восхваления героических подвигов [13, c. 143]. Логично, что начало этому положено в сакское время - эпоху формирования культуры конных воинов.

Захоронение ранних кочевников в экипировке (социально значимых лиц - в парадном костюме), сопровождавших лошадей - в снаряжении - косвенно указывают на веру в посмертное существование воинов и вождей, в том числе в ином мире. Данный аспект имеет обширную историографию [14; 15]. Можно было бы сюда добавить наше предположение о посмертном ритуальном ограблении курганов Каспана-6 в Жетысу, после которого были, вероятно, установлены стелы - как один из заключительных этапов погребально-поминального цикла обрядов проводов и поминовений $[16 ; 17]$. Но это остается лишь на уровне догадок. Вероятно, изваяния в курганах с каменными грядами, сохранявших свое ритуальное значение и в последующую эпоху, отражают линию развития традиции каменных изваяний и антропоморфных стел. Так, в установке средневековых изваяний также отражается связь с почитанием божества войны, вера в загробную судьбу доблестного воина и пр. [15, с. 69].

\section{СПИСОК ЛИТЕРАТУРЫ:}

1. Бейсенов А.З. Арка: значение историко-археологического аспекта в выяснении сущности казахского народного термина // Вестник КазГУ. Сер. ист. 1998. № 12. С. 178-186.

2. Ольховский В.С. Монументальная скульптура населения западной части евразийских степей эпохи раннего железа. М.: Наука, 2005. 299 с.

3. Ермоленко Л.Н., Курманкулов Ж.К. Оригинальное изваяние из фондов карагандинского историко-краеведческого музея // Археология Южной Сибири. К 80-летию Я.А. Шера. Вып. 25. Кемерово: РИО КемГУ, 2011. С. 156-161.

4. Бейсенов А.3., Ермоленко Л.Н. Новые каменные изваяния сакской эпохи из Сарыарки // Вестник КемГУ. 2014. № 3 (59). Т. 3. С. 34-40.

5. Ермоленко Л.Н., Курманкулов Ж.К., Касенова А.Д. Некоторые итоги изучения изваяний раннего железного века Сарыарки // Археологическое наследие Сибири и Центральной Азии (проблемы интерпретации и сохранения): матер. междунар. конф. Кемерово: Кузбассвузиздат, 2016. С. 129-135.

6. Ермоленко Л.Н., К Курманкулов Ж.К., К Касенова А.Д. Новые данные о специфической разновидности изваяний сакской эпохи // Вестник КемГУ. 2015. № 1 (61). Т. 3. С. 26-32.

7. Хабдулина М.К. Каменное изваяние сакского времени из Центрального Казахстана // Сакская культура Сарыарки в контексте изучения этносоциокультурных процессов Степной Евразии: сб. научн. ст., посв. памяти археолога К.А. Акишева. Алматы: Научно-исследовательский центр истории и археологии «Бегазы-Тасмола», 2015. С. 372-375.

8. Гуцалов С.Ю., Таиров А.Д. Стелы и антропоморфные изваяния раннего железного века южноуральских степей // Археология, палеоэкология и палеодемография Евразии: сб. ст. М.: ГЕОС, 2000. С. 226-251.

9. Бейсенов А.З. Памятники раннего этапа тасмолинской культуры // Вестник ТомГУ. История. 2016. № 1 (39). С. 119-126.

10. Бейсенов А.3. Дромосные курганы сакской эпохи урочища Назар // Самарский научный вестник. 2016. № 1 (14). С. 84-93.

11. Бейсенов А.3. Погребально-поминальный комплекс «Курган 37 воинов»// Вестник ЮУрГУ. Сер. Соц.-гум. науки. 2015. Т. 15, № 1. С. 6-12.

12. Савинов Д.Г. Оленные камни в культуре кочевников Евразии. СПб.: СПбГУ, 1994. 208 с.

13. Кубарев Г.В. Древнетюркские изваяния: воплощение эпических героев или воинов-предков? // Археология, этнография и антропология Евразии. 2007. № 1 (29). С. 136-144.

14. Ермоленко Л.Н. Изобразительные памятники и эпическая традиция: по материалам культуры древних и средневековых кочевников Евразии. Томск: Изд-во ТомГПУ, 2008. 288 с.

15. Ермоленко Л.Н. Средневековые каменные изваяния казахстанских степей (типология, семантика в аспекте военной идеологии и традиционного мировоззрения) // Новосибирск: Изд-во ИАЭ СО РАН, 2004. 132 c.

16. Бейсенов А.3., Джумабекова Г.С., Базарбаева Г.А., Баринова Е., Крешиоли Л. Археологические исследования могильника раннего железного века Каспан 6 в Жетысу // Сакская культура Сарыарки в контексте изучения этносоциокультурных процессов Степной Евразии: сб. научн. ст., посв. памяти археолога К.А. Акишева. Алматы: Научно-исследовательский центр истории и археологии «Бегазы-Тасмола», 2015. С. 59-70.

17. Джумабекова Г.С., Базарбаева Г.А. Стелы в погребальном обряде ранних кочевников Казахстана // Актуальные проблемы археологии Евразии: сб. матер. междунар. науч.-практ. конф., посв. 25-летию независимости РК и 25-летию Института археологии им. А.Х. Маргулана. Алматы: Институт археологии им. А.Х. Маргулана, 2016. С. 253-261. (на каз. яз.).

Работа выполнена при финансовой поддержке Министерства образования и науки Республики Казахстан (Проект № 2978/ГФ4 «Саки Тургая: этноархеологические исследования»). 


\title{
NEW SCULPTURE OF THE ERA OF EARLY NOMADS FROM TURGAY
}

(C) 2017

Bazarbayeva Galiya Appazovna, candidate of historical sciences, leading researcher of Prehistoric Department Jumabekova Gulnara Sainovna, candidate of historical sciences, leading researcher of Prehistoric Department A.Kh. Margulan Institute of Archaeology (Almaty, Republic of Kazakhstan)

Abstract. The paper introduces a stone sculpture of the era of early nomads from Turgay into scientific use. This region is the western wing of Saryarka. In 2015-2016 the monuments of the Tasmola culture were researched. The finding is a rather rare case of the location of the statue in the mound complex with stone ridges. Field researches of the construction with a statue have shown an unusual character of its site. Laconism in the transfer of the anthropomorphic image finds parallels in the sculptures of Central Kazakhstan of early nomads. Sculptures from Central Kazakhstan are similar to the sculptures of the Northern Black Sea coast and the South Ural steppes based on their purpose and pictorial techniques. It is assumed that the aspect of military glory, traced in medieval sculptures, originated in the era of the early nomads, and the evidences are the findings of stele and stone sculptures.

Keywords: Turgay; Central Kazakhstan; early iron age; Tasmola culture; Scythian; mound; field researches; medieval; nomads; statue; sculpture; kurgans with stone ridges; excavations; complex; fence; constructive element; funeral rite; bodily attributes; stelae; anthropomorphic image; signs.

УДК 94 (367) : $929.5 \ll 15 »$

\section{КАШИНСКИЕ КНЯЗЬЯ В 60-Е - НАЧ. 80-Х ГОДОВ ХIV ВЕКА}

(C) 2017
Абуков Сергей Навильевич, кандидат исторических наук, старший преподаватель
кафедры историографии, источниковедения, археологии и методики преподавания истории Донецкий национальный университет (2. Донецик, Донецикая Народная Республика)

\begin{abstract}
Аннотащия. В статье автор исследует значение Кашина как крупного центра Тверского княжества в период правления Василия Михайловича и противостояния Москвы и Твери, неустойчивую позицию кашинских князей, обусловленную борьбой партий в среде местной правящей элиты, оказавшейся между двумя центрами силы. В результате часть элиты продолжала ориентироваться на Тверь, в то время как другая отдавала предпочтение Москве. Последняя позиция взяла верх, что обусловило отказ кашинского князя от договора с Михаилом Александровичем и его участие в походе на Тверь в 1375 году. Особое внимание в статье уделено росту местного сепаратизма, судьбе Кашинского княжества по договору 1375 г., закрепившему выход его изпод верховной власти Твери, а также краткому периоду его формальной независимости и обстоятельствам его возвращения под власть Твери в 1382 г.
\end{abstract}

Также анализируется влияние родственных связей кашинских князей, в первую очередь брак кашинского князя Михаила Васильевича и московской княжны Василисы Семеновны, причины, обстоятельства и значение этого брака в свете московско-тверских отношений в 60-80-е гг. XIV в. в общем контексте брачных союзов двух ведущих княжеств Северо-Восточной Руси.

Ключевые слова: Василий Михайлович; Михаил Васильевич; Василий Михайлович (II); Михаил Александрович; Семен Гордый; Мария Александровна; Дмитрий Донской; Кашин; Москва; Тверь; князь; брак; родственные связи; конфликт; XIV век.

Соперничество Москвы и Твери стало одним из ключевых событий борьбы за лидерство в СевероВосточной Руси в первой четверти XIV в. Фактически именно эти два центра, возглавляемые правящими линиями потомков Ярослава Всеволодовича, явились теми княжествами, которые могли возглавить процесс объединения русских земель. Во второй половине века характер борьбы между ними изменился. Тверь уже не имела возможности самостоятельно противостоять Москве, вынужденно опираясь на внешние силы, что во многом предопределило ее окончательное поражение. Часто это противостояние отличалось драматизмом и ожесточением сторон. Однако московско-тверские отношения были сложными и многогранными. Времена открытых конфликтов и войн сменялись годами относительно мирного существования и союзничества. Одним из показательных и важных форм взаимодействия двух княжеских домов были династические браки, ставшие существенным фактором эпохи феодализма. Это был своеобразный маркер, демонстрирующий намерения и планы сторон. В этом контексте обращает на себя внимание брак дочери Семена Гордого и сына великого князя тверского Василия Михайловича Кашинского, имевший далеко идущие последствия для московко-тверских отношений в период возобновления московко-тверской войны.

Однако особого внимания заслуживают сами кашинские князья в этот драматичный исторический период и их княжество, а также краткие годы существования формально независимого Кашинского княжества, а также обстоятельства, в результате которых Кашин вернулся под власть Твери. Изучение круга этих вопросов позволяют глубже понять всю сложность и противоречивость процесса возвышения Москвы и истории правящих феодальных элит Северо-Восточной Руси. Несмотря на очевидную значимость проблемы, она не получила пристального внимания историков.

События, связанные с Кашином в этот период, упоминали крупные историки, исследовавшие этот период, однако в общем контексте истории Руси [1- 